\title{
Is There a Bias Toward Contributing to Local Public Goods? Cultural Effects
}

\author{
Calvin Blackwell \& Michael McKee
}

\begin{abstract}
A series of experiments was designed and implemented to investigate cross-cultural differences in preferences for contributing to local public goods. The research investigates differences between contributions made by participants from the United States, Russia and Kazakhstan. In these experiments each participant has three options: keep money for herself, contribute to a public good that benefits a small group (the local good), or contribute to a public good that benefits the entire group (the global good). The researchers find significant differences in contribution patterns across the three cultures, and find that all participants contribute significantly more to the small group public good than to the large group public good.
\end{abstract}

\author{
Keywords \\ Public goods \\ Experiment \\ Voluntary contribution mechanism \\ Culture
}




\section{Introduction}

Pure public goods are defined as having the properties of being non-rival in consumption (once produced the entire good can be enjoyed by all) and non-excludable (no one can be prevented from enjoying the good on the basis that he has not contributed to meeting the cost of providing the good). If individuals are requested to voluntarily contribute to the provision of such goods, the rational response of a selfinterested individual is to contribute zero, or free ride. The aggregate contribution is, then zero. We rarely observe such behavior in the field or the lab, even under the most carefully controlled experimental settings (see Isaac et al. 1984). Several reasons have been advanced to explain positive contributions including altruism (Andreoni 1995), reciprocity (Ledyard 1995), and cultural norms (see Henrich 2000; Henrich et al. 2001; Gurven 2004).

An interesting class of public goods is those that allow for limited exclusion based on location or some other readily identifiable characteristic such as age or gender. Such local public goods can be contrasted with global public goods which are available to the larger set of all individuals. An example of a local public good would be police protection which provides the good only to those living within a defined geographic area (a city, for example) while an example of a global public good would be national defense which provides the good to the residents of the entire country. This taxonomy provides for a test of the effects of culture on voluntary contribution since we can investigate the propensity to contribute to the local versus global public good when the services are substitutes. In a laboratory setting we implement local and global public goods and elicit voluntary contributions to these to investigate the effects of cultural norms on cooperative behavior. We conduct these experiments in three countries, the U.S., Kazakhstan, and Russia. Our rationale for selecting these is discussed below.

The path by which culture affects willingness to contribute to public goods continues to be a matter of debate. Casual field observations suggest that some cultures are innately more cooperative. Social scientists have used a variety of techniques to investigate cultural variation in characteristics like cooperation, trust and reciprocity. Disentangling behavioral motives in field settings is difficult due to the presence of confounding factors, and many researchers turn to laboratory or quasi-laboratory settings. In the context of the distinction between local and global public goods discussed above, an understanding of motives may be obtained through observing relative propensities for contributing to a public good that is enjoyed only by one's near neighbors (a local public good) to contributing to one that is available to a larger body (a global public good).

Previous research has consistently shown differences in experimental behavior across groups of participants from different cultures but this literature has largely been limited to merely showing that an effect of culture exists, with few papers (see Chen and Tang 2009 and Cummings et al. 2009 as examples), making the serious effort to use experiments to test hypotheses about the precise effects of particular cultures on behavior. We extend the literature on economics and culture by exploiting some of Hofstede's (2001) dimensions of culture to generate testable hypotheses about the effect of culture on the propensity to contribute to local versus global public goods. We 
explore differences among subjects in the United States, subjects in Russia, and subjects in a former member of the Soviet Union (Kazakhstan). The setting is a voluntary contribution game in which participants may choose between contributing to the provision of a local public good and/or a global public good. With this richer environment subtler effects of culture may appear than can be found within a simple single public goods setting. We find differences in the behavior of our experimental participants across the three countries and we find that Hofstede's dimensions help to explain these differences.

\section{The Effects of Culture on Cooperation Experimental Findings}

Two types of experiments, the ultimatum game and the voluntary contributions public goods game, have been extensively examined across cultures. Since both games offer a measure of cooperative behavior it is useful to recount the results of both. In the ultimatum game, a proposer makes an offer to split a sum of money with a second participant, called the receiver. If the proposer's offer is accepted, then the proposer and the receiver split the money according to the proposer's offer. If the receiver rejects the offer, then both participants earn nothing. In the public goods game each participant is given a sum of money that must be allocated to one of two accounts-a personal account and a group account. Money allocated to the personal account is kept by the participant, but money placed in the group account is multiplied by a parameter $(>1)$ and the resulting amount is divided (usually equally) among the members of the group.

Both of these games share similar non-cooperative Nash equilibria in that the equilibria are not "nice"-in the ultimatum game the Nash equilibrium is to offer the smallest possible offer greater than zero, and in the public goods game the Nash equilibrium is for each participant to contribute zero to the group account, which results in the lowest possible payout to the group.

Observed behavior in these two games differs dramatically from the Nash equilibria. In ultimatum games proposers typically offer 40 to $50 \%$ of the available money (Roth 1995), while in the voluntary contribution public goods game participants typically contribute between 40 and $60 \%$ of their available funds to the group good (Ledyard 1995). The typical interpretation of this behavior is the existence of pro-social preferences, although the exact nature of the preferences is a source of ongoing discussion in the literature. Presumably pro-social behavior is to at least some extent learned behavior, and therefore likely has cultural content, making these games excellent tools for studying the effect of culture.

Although Roth et al. (1991) found little difference in play of the ultimatum game across some industrial societies, they did report that US participants made higher offers than Japanese participants.1 Henrich et al. (2001) found significant differences across cultures in the play of the ultimatum game. Though participants from the USA typically offer between 40 and $50 \%$ of the available funds, the average participant from the Machiguenga society in Peru offered $26 \%$ of the available funds, and the average participant from the Lamelara society in Indonesia offered 58\%! Chen and Tang (2009) 
found differences in the behavior of Tibetan and Chinese participants that could be attributed to differences in the cultures of the two groups. Okada and Riedl (1999) did not uncover any effect of culture on play in the ultimatum game between groups of participants from Austria and Japan.

As with the ultimatum game, culture has been shown to have an effect on behavior in the linear public goods game. For example, Burlando and Hey (1997) generated data indicating that residents of the UK were less likely to contribute to the group account than Italian residents. Ockenfels and Weimann (1999) found that East Germans were more likely to free-ride than West Germans, and attribute the difference in the two regions to differing economic and social histories. One exception to this trend is a paper by Brandts et al. (2004) in which the authors found only minor differences in contribution behavior between participants from Japan, the Netherlands, the US and Spain.

\section{Hofstede's Cultural Taxonomy}

Hofstede (2001) analyzed questionnaire results from over 50 nations (including the USA and Russia, but not Kazakhstan) to define five dimensions of culture: Uncertainty Avoidance, Individualism/Collectivism, Masculinity/Femininity, Power Distance, and Long Term/Short Term Orientation. The first three of these dimensions seem relevant to our experiment: Uncertainty Avoidance, Masculinity/Femininity, and Individualism/Collectivism. Hofstede describes Uncertainty Avoidance as follows:

$\ldots$ on the national cultural level, tendencies toward prejudice, rigidity and dogmatism, intolerance of different opinions, traditionalism, superstition, racism and ethnocentrism all relate to a norm of intolerance of ambiguity that I have measured and expressed in a national Uncertainty Avoidance Index. (p.146).

The Masculinity/Femininity dimension contrasts the degree to which members of a society value "masculine" goals like advancing one's career and earning money versus more "feminine" goals like building relationships and helping others. The Individualism/Collectivism dimension attempts to measure the relationship between the individual and the collective. On these three measures, Hofstede reported that the US had a score of 46 for Uncertainty Avoidance, a score of 62 on Masculinity/Femininity, and a score of 91 on Individualism/Collectivism. Russia, on the other hand, had a score of 95 for Uncertainty Avoidance, a score of 36 for Masculinity/Femininity, and a score of 39 on Individualism/Collectivism. In other words, Hofstede found that people from the US tend to be more trusting of strangers, less co-operative, less sensitive to social pressure, and less likely to put the welfare of the group above the welfare of the individual than people from Russia.

\section{Predictions}

Hofstede's dimensions suggest our predicted ranking of the propensity to contribute to public goods and the relative propensity to contribute to the local public good across the countries we investigate. We predict that participants from more individualistic cultures (like the USA) will contribute less to both public goods than participants from more collectivist cultures (like Russia). A higher level of uncertainty avoidance would suggest 
greater propensity to contribute at local levels as compared to more global levels (reflecting a lack of trust for people outside of the group). More masculine cultures emphasize material gain over personal relationships and so may be more inclined to generate "selfish" behavior (i.e., non-contribution to the public good) instead of more cooperative behavior. It may also be easier for participants from more feminine cultures (like Russia) to establish and monitor cooperation throughout the experiment, leading to increased public good contributions. The measures on the three dimensions (Uncertainty Avoidance, Individualism/Collectivism and Masculinity/Femininity) all suggest that contributions to both public goods will be higher in Russia than in the USA.

Although Hofstede did not sample individuals from Kazakhstan, and hence does not provide measures on his five dimensions for this country, we can make predictions regarding the behavior of participants from Kazakhstan on the basis of their recent history. Specifically, we predict that participants from Kazakhstan will exhibit slightly lower contributions to the public good than participants from Russia, but more than participants from the USA. In terms of the relative propensity to contribute to the local public good, given that Kazakhstan was a Soviet satellite for more than 70 years, and experienced considerable exploitation during that period, we expect the highest preference toward contributing to local public goods among the Kazakhstan subjects.

\section{Experimental Design}

In the series of experiments reported here, the participants are simultaneously assigned to two groups, a neighborhood ('local') group (defined by color: red, blue or black), and the global group, which always consists of all participants in the experiment. The players are not told how many rounds will be played; therefore they are playing a finitely repeated game with an unknown but non-zero probability of continuing. Our experimental treatment is the cultural background of the participants in the sessions and our objective is to ascertain whether this background has a predictable effect on the propensity to contribute to the local public good rather than the global public good. Further, we investigate whether there is a bias toward not contributing to public goods in general that can be explained by cultural differences.

All the details of the experimental design are explained in the instructions, and hence are common knowledge for all participants. Each participant begins with an initial allocation of tokens, Wi=100.2 The participant's task is to allocate these tokens among three accounts: private, local public good and global public good. There are either four or five persons per local group and three local groups in the session (12 or 15 participants). The differences in group sizes were due to participant no-shows. The instructions (in English or Russian,3 depending upon the participants' native tongue) are read aloud to the participants while they follow along on their own copies. To ensure consistency across sessions only these written instructions are provided to the subjects (although clarification questions were answered). The instructions describe the accounts as follows. The first account, named the personal account, yields a one-to-one return in tokens. The second account, designated the local account, is essentially a linear public good with a constant return of .3 tokens to the individual, but 1.2 tokens to the group if there are four persons per group or 1.5 tokens to the group if the group 
consists of five persons. Therefore the marginal per capita return (MPCR) to the individual is 0.3. The third account, or global account, has a MPCR of 0.1. The participants may allocate their tokens to their personal account, to the local (color) public good, or to the global public good.

Each individual is randomly assigned to a local group identified by a color (red, blue and black). These are hand run experiments conducted in a seminar room. In front of each participant is a table tent identifying their group color. In the US experiments, participants were spread among four tables, with two or three participants per table. In Kazakhstan and Russia, participants sat at individual desks in view of each other. In all locations color group members were scattered throughout the room. For example, an individual in the black group might be seated next to an individual from the blue group. In all three countries, all participants could see all the other participants and their corresponding color identities. In addition to being a member of a color (local) group, each individual is a member of the global group consisting of all participants in the experiment.

Each round the participants enter their choices of allocation among the three options on a ballot that is collected by the experimenter. The allocations are entered into a spreadsheet program that computes the payoff to each of the separate accounts as well as the total for the participant for the round. The person running the experiment records these payoffs on the participants' ballots and the ballots are returned to the participants so that they are informed of the outcomes (total contributions and their returns from the three funds). The participants have a minute to review the information and a new round begins. The participants are not told the number of rounds that will be conducted and receive a new ballot for each round. In fact, two practice rounds and ten recorded rounds were planned for each treatment. Participants were informed the experiment would last approximately one hour. Due to communication through translators we were unable to complete 10 rounds in both sessions conducted in Russia and in one session run in Kazakhstan. At the end of the session each participant was paid on the basis of his/her earnings in the experiment at the rate of 1 US cent/token in the US, at the rate of 0.25 Russian rubles/token in Russia, and at the rate of 0.1 Kazakhstan tenge/token in Kazakhstan. These payments were scaled in such a way that a typical student participant would earn approximately twice the going wage for unskilled labor (for example, in the US the average payment was about $\$ 14$ for one hour, approximately twice the minimum wage).

The USA participants are undergraduate students, recruited from introductory economics classes at the University of New Mexico. All the participants from the former Soviet Union are business students from three universities: Ural State Polytechnic University in Ekaterinburg, Russia; Northern Kazakhstan State University in Petropavlovsk, Kazakhstan; the Kazakhstan State Academy of Management in Almaty, Kazakhstan.5 Participants were recruited the same way in all three countries, by inclass announcements made during the course of the semester. 


\section{Analysis}

The results for these experiments are reported in Figs. 1, 2, 3, 4 and 5 and Tables 1 and 2. Figure 1 reports the overall contribution (as a fraction of income) to both public good accounts. Data are organized by location. The results indicate that overall contributions do differ by country, with participants from Russia contributing more to the two public goods than participants from the USA or Kazakhstan, and participants from Kazakhstan contributing more to the two public goods than participants from the USA. Figures 2 and 3 show contributions to the local public good and the global public good, respectively, and follow the same basic pattern: Russian contributions > Kazakhstan contributions > USA contributions. These basic data patterns are consistent with the hypotheses generated from Hofstede's measures.

As participants gain more experience, their contribution behavior may change, depending upon their cultural background. In Fig. 1 we see that the contribution rates for Russian and USA participants change little across the 5 rounds when compared to the participants from Kazakhstan, whose contributions start high and then drop to be as low as the contributions from the USA participants. Figure 2 indicates that these different patterns of behavior across rounds are primarily a result in changes in contribution rates for the local public good. We see that Russian participants slightly lower their contributions, USA participants slightly increase their contributions, while participants from Kazakhstan drop their contributions from approximately $35 \%$ to $20 \%$. In Fig. 3, the overall pattern appears to be for contributions to the global public good to change very little across rounds, regardless of culture.

Figure 4 depicts the ratio of contributions to the local public good divided by contributions to the global public good. Here the difference appears to be between participants from the USA and participants from Russia and Kazakhstan. Perhaps because residents of the USA have a narrower, more localized view, they tend to contribute a much higher proportion to their local public good. Note that these results contradict the hypothesis that participants from high Uncertainty Avoidance cultures (like Russia) would be more likely to contribute to the local public good

Overall Contributions to Both Public Goods as a Percentage of Total Tokens

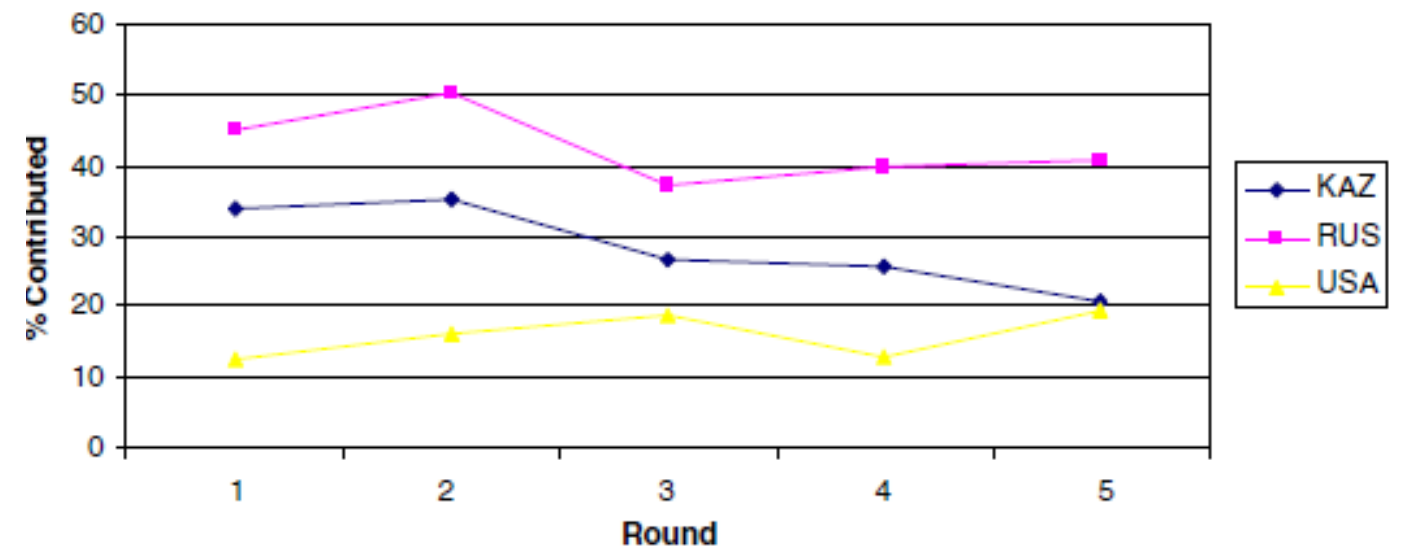

Fig. 1 Overall contributions to both public goods by round 


\section{Contributions to Local Account as a Percentage of Total}

Tokens

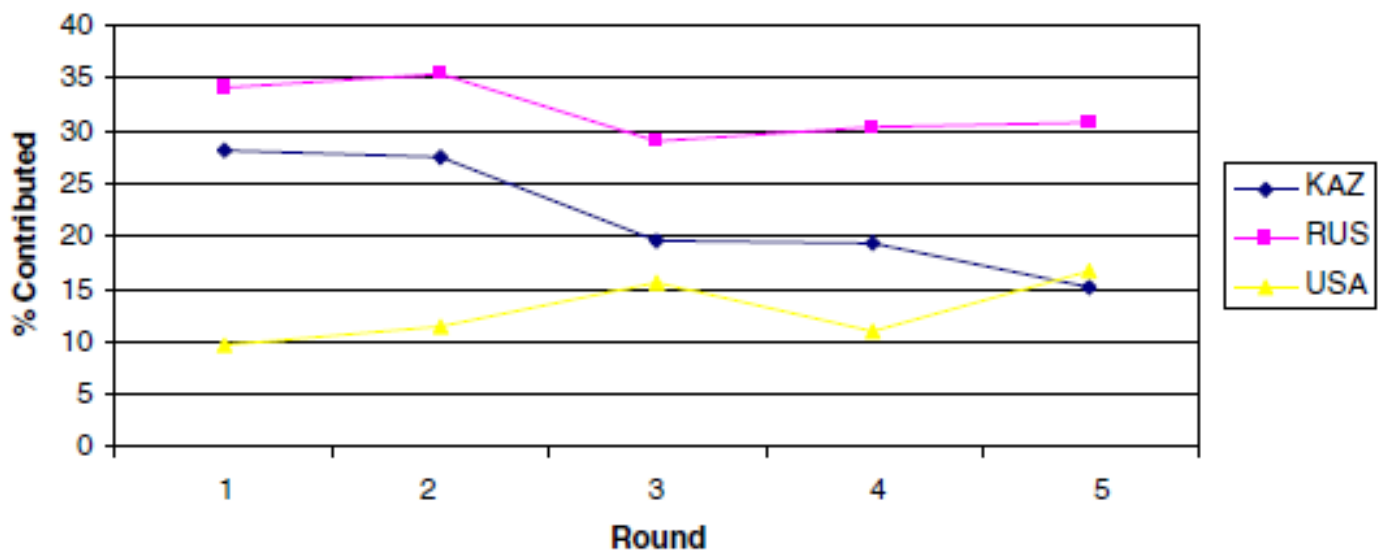

Fig. 2 Contributions to local account by round

than participants from low Uncertainty Avoidance cultures (like the USA). Furthermore, we do not see relatively higher contributions to the local public good from participants from Kazakhstan as we expected should be the case given Kazakhstan's recent history.

In Fig. 5 we show a histogram of the proportion of participants who contribute a given proportion of their endowment to the public goods. The main difference in this diagram seems to be between the behavior of USA participants and the participants from Russia and Kazakhstan. The USA participants have a distribution that is bunched at the low end, with very few participants contributing more than $30 \%$ of their endowment. The Russian distribution is more uniform, with almost as high a proportion of participants contributing 100\% (approximately 15\%) as contribute less than 10\% (about 16\%). The distribution of contributions from Kazakhstan is somewhere between the distributions of Russia and the USA, but is more like Russia than the USA.

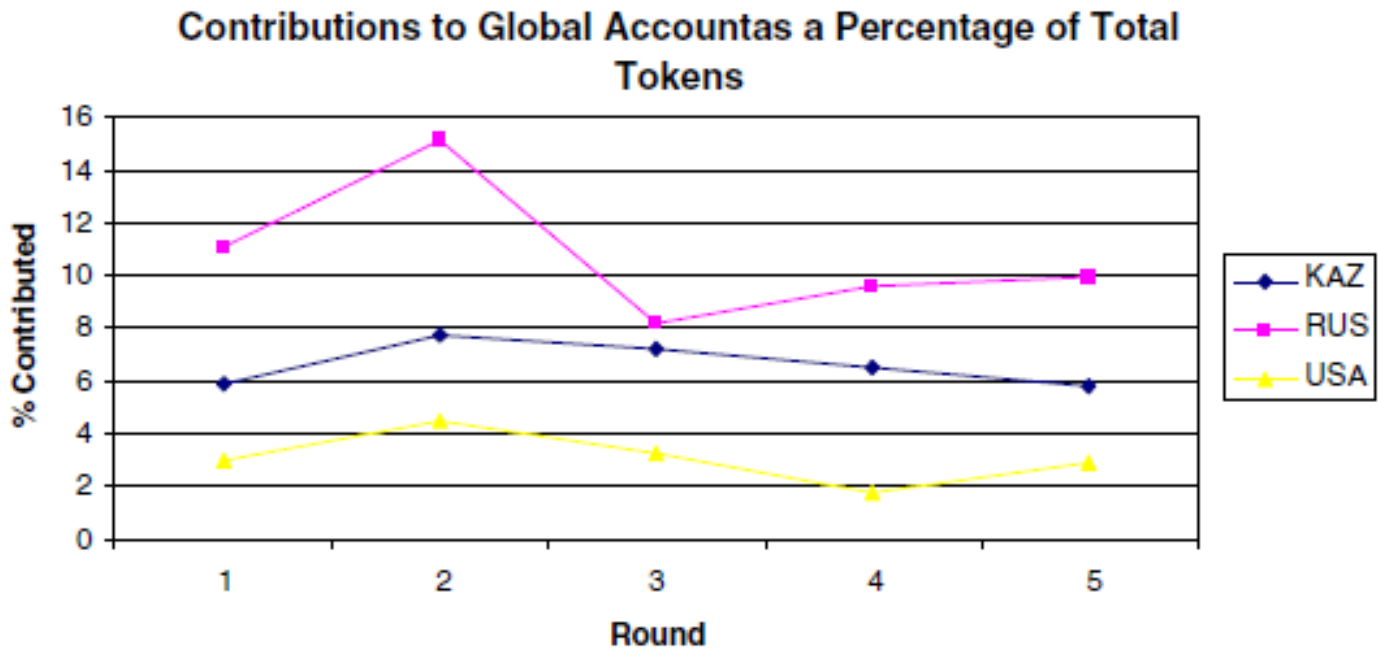

Fig. 3 Contributions to global account by round 


\section{Contributions to Local Account Divided by Contributions to Global Account}

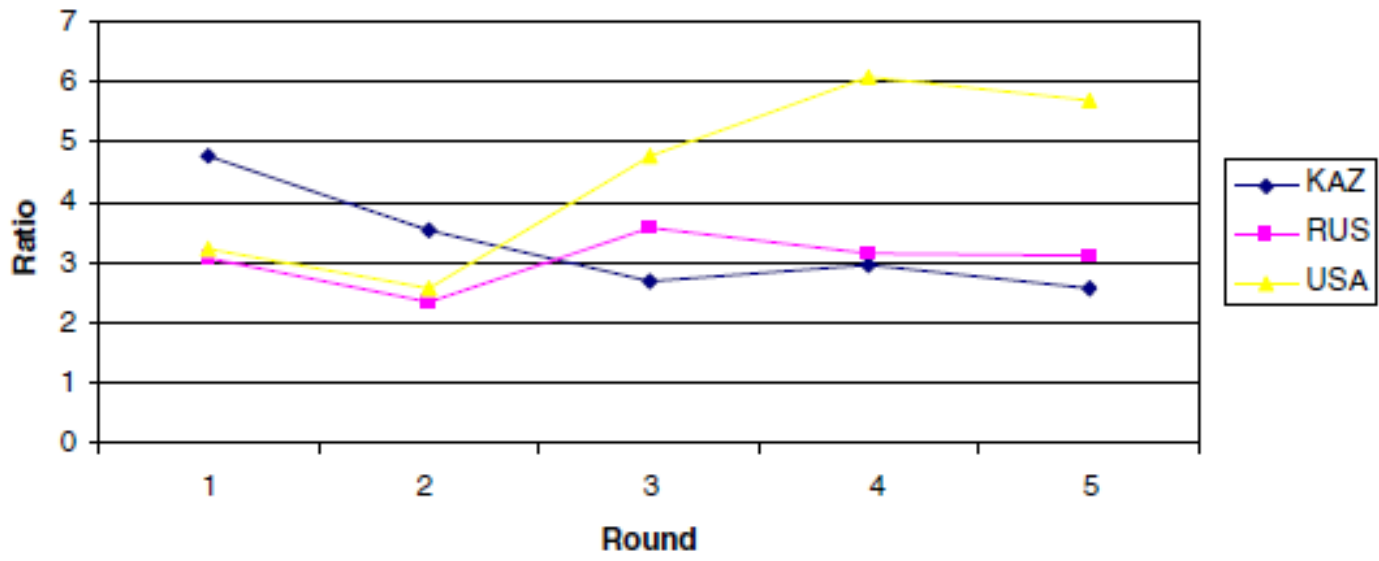

Fig. 4 The ratio of contributions to the local account to contributions to the global account by round

Summary statistics are reported in Table 1, while the results of several statistical tests are reported in Table 2. Notice that across all three countries, the lowest proportion of contributions always goes to the global public good. This result is consistent with earlier experimental work (Blackwell and Mckee 2003) and also coincides with Adam Smith's (2002: 1759) idea of concentric circles of benevolence, in which other regarding preferences fall as one moves from those closest to the individual.

We ran a series of ANOVA tests on the ranked observations of contributions to each of the three accounts. We performed these analyses on the entire set of data, and on two subsets of data, the round one data and the round five data. We used these two subsets because the round one data will capture the initial behavior of participants (before any feedback is provided), while round five is the latest round for which we have observations in all five locations. The results of these tests are reported in Table 2.

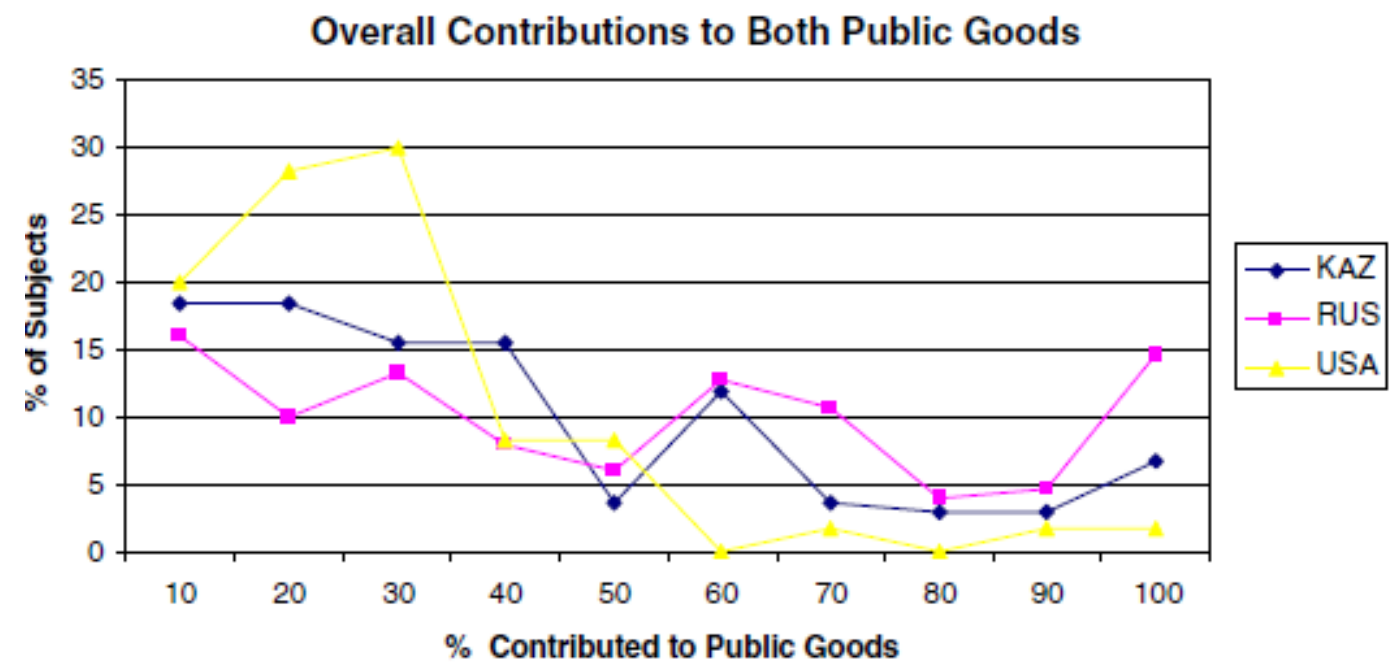

Fig. 5 Overall contributions to both public goods 
Table 1 Overall contribution rates averaged across rounds 1-5

\begin{tabular}{lccc}
\hline & $\begin{array}{c}\text { \% Contributed to } \\
\text { Personal Account }\end{array}$ & \% Contributed to Local P.G. & \% Contributed to Global P.G. \\
\hline Kazakhstan & 71.4 & 21.9 & 6.7 \\
Russia & 57.3 & 31.9 & 10.8 \\
USA & 84.0 & 12.9 & 3.1
\end{tabular}

Generally we find significant differences across cultures, with US students tending to place most of their tokens in the private good account. The trend, over rounds, is for the difference across cultures to shrink. The participants from Kazakhstan move toward the non-cooperative equilibrium fastest, contributing relatively more to the private good as they become more familiar with the game. The Russians consistently contribute the least to the private good.

Confirming the impression given by Figs. 1, 2 and 3, the results show less difference across cultures in contributions to the local public good than for the private good. Russians seem to contribute more to the local public good than either the participants from the United States or Kazakhstan. We also see that there is no significant difference across cultures in the level of contributions to the global public good. There are generally low levels of contributions to the public good by participants from all three cultures.

Notice that first period contribution rates are similar within cultural groups. However, fifth period rates are not similar within the Russian group. Most of the fifth period difference seems to be from this one treatment. Perhaps cultural effects are complicated-for example, the propensity to cooperate might allow for diverging paths of play in this game.

Table 2 Differences in contributions by country across rounds and goods

\begin{tabular}{|c|c|c|c|}
\hline \multirow[t]{2}{*}{ Good } & \multicolumn{3}{|l|}{ Round } \\
\hline & Overall & 1 & 5 \\
\hline Personal Account & $\begin{array}{l}\mathrm{F}^{\mathrm{obr}}=12.67(p=0.001) \\
\text { Significant Differences: } \\
\text { USA }>\text { Kazakhstan } \\
\text { USA }>\text { Russia } \\
\text { Kazakhstan }>\text { Russia }\end{array}$ & $\begin{array}{l}\mathrm{F}^{\mathrm{obr}}=6.18(p=0.004) \\
\text { Significant Differences: } \\
\text { USA }>\text { Kazakhstan } \\
\text { USA > Russia }\end{array}$ & $\begin{array}{l}\mathrm{F}^{\text {obs }}=5.04(p=0.009) \\
\text { Significant Differences: } \\
\text { Kazakhstan > Russia }\end{array}$ \\
\hline Local P.G. & $\begin{array}{l}\mathrm{F}^{\mathrm{obr}}=6.54(p=0.002) \\
\text { Significant Differences: } \\
\text { Russia > USA }\end{array}$ & $\begin{array}{l}\mathrm{F}^{\mathrm{obr}}=4.55 \quad(p=0.014) \\
\text { Significant Differences: } \\
\text { Russia > USA } \\
\text { Kazakhstan > USA }\end{array}$ & $\begin{array}{l}\mathrm{F}^{\mathrm{obs}}=1.81 \quad(p=0.171) \\
\text { Significant Differences: } \\
\text { Russia > Kazakhstan }\end{array}$ \\
\hline Global P.G. & $\begin{array}{l}\mathrm{F}^{\mathrm{obr}}=1.39(p=0.251) \\
\text { Significant Differences: } \\
\text { None }\end{array}$ & $\begin{array}{l}\mathrm{F}^{\mathrm{obr}}=1.06(p=0.354) \\
\text { Significant Differences: } \\
\text { None }\end{array}$ & $\begin{array}{l}\mathrm{F}^{\mathrm{obs}}=0.19(p=0.824) \\
\text { Significant Differences: } \\
\text { None }\end{array}$ \\
\hline
\end{tabular}




\section{Conclusions}

Several conclusions can be drawn from the observed behavior in these experiments:

1. Cultural differences exist. US participants seem to play this public goods game less cooperatively than either participants from Kazakhstan or Russia, with Russians appearing to be the most cooperative. The behavior of participants from the three cultures is qualitatively different.

2. Differences across cultures are greatest initially and then decrease. There are more significant results when comparing the results for round 1 than for any other set of comparisons. This result suggests that culture may have an impact in setting up the initial expectations of the participants, but that the importance of that expectation falls as participants learn the game. However, we cannot rule out the potential for cooperative tendencies to create diverging results over time; in other words, there may be some sensitivity to initial conditions due to culture. (For example, the USA participants seem to evolve relatively more "localized" preferences for contributing over time than do the participants from Russia or Kazakhstan.)

One interesting result comes from Fig. 5-the proportion of participants contributing less than $10 \%$ is essentially the same across countries. This suggests something about how culture and genetics may combine to impact behavior. A common finding (e.g., see results reported by Andreoni 1995) in public goods experiments in the west is that a small proportion of participants always play the Nash equilibrium strategy of contributing zero (or close to it). If this proportion is constant across cultures, this result could buttress the argument that attitudes towards cooperation are at least partly genetically determined, and not learned.

The effect of culture can be overemphasized. Note that for all three groups, contributions to the local public good were always greater than contributions to the global public good, suggesting perhaps a universal preference for smaller groups when contributing to linear public goods. This result may be due to the greater ease of maintaining cooperation in a small group, or perhaps Adam Smith's conjecture about expanding circles of benevolence may apply to all cultures.

3. Hofstede's measures seem to accurately predict behavior-participants from Russia contribute more to public goods than do participants from the USA. On the dimensions of Masculinity/Femininity and Individualism/Collectivism, the USA and Russia exhibit profound cultural differences, with the USA being a highly masculine, individualist culture and Russia being a highly feminine, collectivist culture. If Kazakhstan culture lies somewhere in between on these two dimensions (which seems likely given that the USA and Russia are relative outliers on these two dimensions), then it seems likely behavior in the public goods game should fall somewhere in between, and it does. In addition, we can consider the inverse of the previous statement. Although Hofstede did not 
measure the culture of Kazakhstan, we can use the results of these experiments to estimate where Kazakhstan might score.

Culture evidently has an effect on play in this public goods game. These experiments support the hypothesis that not only is the mean contribution level to public goods different across cultures, but the distribution of contributions is different across participants and rounds. Although the participants in these experiments were in many ways similar (all were university students), their play of the game had many dissimilarities. These results provide evidence that culture can have a strong impact on individual willingness to cooperate.

One interpretation of what we have done is to perform a sort of triangulation between behavior in incentivized experiments and Hofstede's measures of culture. This technique could also be used to triangulate with other measures of culture (for example the World Values Survey). Most other papers examining the issue of culture and economics in an experimental setting have been content to merely show there is a difference and make some fairly ad hoc statements about where that difference comes from. For example, Henrich et al. (2001) show that members of gift-giving cultures tend to make larger offers in the Ultimatum Game. However, other than the qualitative analysis that these are gift-giving cultures, there is no measure taken of this cultural trait. Only one other paper has gone so far as to test the impact of a cultural trait through an experiment-Chen and Tang (2009). We hope that in the future more of this type of triangulation between survey research and experimental research will be used to improve measures of culture.

\section{Acknowledgment}

The authors would like to thank William Gilchrist IV, Grieta Gilchrist, Laird Graeser, Dastan Bezkazir, Inna Iljina, Leonid Fridman and the administrations and students of Northern Kazakhstan University, the Kazakhstan State Academy of Management, and Ural State Polytechnic University for their help. The authors would also like to thank participants at the 2000 Economic Science Association Regional Meetings.

\section{Appendix: Experimental Instructions Welcome to the Experiment!}

We are conducting an experiment that helps us understand how people make economic decisions. Experimental economics is an important and interesting way for us to learn about how people make economic decisions, but in order for these experiments to be successful we must follow some simple yet very important rules:

- Please do not speak out loud.

- Do not communicate with anyone in the room but the coordinator.

- If you have a question raise your hand and a coordinator will visit your station. 


\section{To Begin}

1. We will read the instructions aloud together.

2. We will do two practice rounds of the experiment.

3. Be patient! Most of your questions will be answered by doing the practice rounds.

4. Follow the rules, relax and have fun!

\section{Overview}

This is an experiment in the economics of group decision-making. Your problem is to decide how to divide your tokens between two types of accounts. You can contribute tokens to your personal account, in which case each token generates a cash return to you (and you alone); or you may put tokens into one of two group accounts. Tokens placed in a group account yield a lower return to you. However, every member of the group receives the same return for every token that other members of the group place in the group account. Similarly, you receive a return for every token that other members of the group place in the group account.

You will be divided into groups of four. These groups are identified by color. The three groups are: red, blue, and black. You will be a member of one of these three groups. There are two types of group account. The colored group account yields a return only to the members of the group. For example, when members of the red group contribute to the red group account, the returns from this account go only to members of the red group. The global account gives a return to all the subjects in the experiment. Contributions made to the global account yield a return to members of the red, blue, and black groups.

\section{How the Experiment is Organized}

- We will play two practice rounds. The results of the practice rounds will not count towards your payoff at the end of the experiment.

- We will play several rounds where the results of each round will determine your payoff at the end of the experiment.

- The currency used in this experiment is tokens. Your payoff at the end of the experiment will depend on how many tokens you earn. The more tokens you win, the more money you will earn.

\section{Rounds}

- At the beginning of the round you will be given 100 tokens.

- You may assign these tokens any way you like between three accounts: your personal account, your group account, and the total account.

- You must allocate all your tokens.

- You may not allocate more than 100 tokens.

- After you have made your decision, the experimenter will collect your decisions and tally the results.

- You will be informed of the results of the round. You will know your total return, as well as the return to you from the group account and from the global account. 


\section{Accounts}

- The return to you from your personal account is one-to-one. For every token you allocate to your personal account, you receive one token.

- The return to the group is account is 3 tokens for every 10 tokens contributed to the account. All members of the group receive 3 tokens for every 10 tokens contributed to the account.

- The return to the global account is 1 token for every 10 tokens contributed to the account. All persons in the experiment receive 1 token for every 10 tokens contributed to the account.

- You are not required to contribute to either the group or global account.

- All members of the group receive the return from the group account, whether they contribute to that account or not. All persons in the experiment receive the return from global account whether they contribute to that account or not.

\section{Earnings}

- Each token is worth 1 cent.

- Winnings will be rounded up to the nearest quarter. 


\section{References}

Andreoni, J. (1995). Cooperation in public goods experiments: kindness or confusion? American Economic Review, 85, 891-904.

Blackwell, C., \& McKee, M. (2003). Only for my neighborhood? Preferences and voluntary provision of local and global public goods. Journal of Economic Behavior and Organization, 52, 115-131.

Brandts, J., Saijo, T., \& Schram, A. (2004). How universal is behavior? A four country comparison of spite and cooperation in voluntary contribution mechanisms. Public Choice, 119, 381-424.

Buchan, N. R., Croson, R. T. A., \& Johnson, E. J. (1999). Understanding what's fair: Contrasting perceptions of fairness in ultimatum bargaining in Japan and the United States. Discussion Paper. University of Wisconsin.

Burlando, R.,\&Hey, J. D. (1997).Do Anglo-Saxons free-ridemore? Journal of Public Economics, 64, 41-60.

Chen, K., \& Tang, F.-F. (2009). Cultural differences between Tibetans and Ethnic Han Chinese in ultimatum game bargaining experiments. European Journal of Political Economy, 25, 78-84.

Cummings, R., Martinez-Vazquez, J., McKee, M., \& Torgler, B. (2009). Tax morale affects tax compliance: evidence from surveys and an artefactual field experiment. Journal of Economic Behavior and Organization, 70, 447-457.

Gurven, M. (2004). Does market exposure affect economic game behavior? The ultimatum game and the public goods game among the Tsimané of Bolivia. In J. Henrich et al. (Eds.), Foundations of human sociality (pp. 194-231). New York: Oxford University Press.

Henrich, J. (2000). Does culture matter in economic behavior? Ultimatum game bargaining among the Machiguenga of the Peruvian Amazon. American Economic Review, 90, 973-979.

Henrich, J., Boyd, R., Bowles, S., Gintis, H., Fehr, E., \&McElreath, R. (2001). In search of homo economicus: behavioral experiments in 15 small scale societies. American Economic Review, 91, 73-78.

Hofstede, G. (2001). Culture's consequences. Thousand Oaks: Sage.

Isaac, R. M., Walker, J., \& Thomas, S. H. (1984). Divergent evidence on free riding: an experimental examination of possible explanations. Public Choice, 43, 113-149.

Ledyard, J. O. (1995). Public goods: A survey of experimental research. In J. Kagel \& A. Roth (Eds.), The handbook of experimental economics (pp. 111-181). Princeton: Princeton University Press.

Marwell, G., \& Ames, R. E. (1981). Economists free-ride, does anyone else? Experiments on the provision of public goods. Journal of Public Economics, 15, 295-310.

Ockenfels, A., \& Weimann, J. (1999). Types and patterns: an experimental East-West-German comparison of cooperation and solidarity. Journal of Public Economics, 71, 275-287. 
Okada, A., \& Riedl, A. (1999). When culture does not matter: Experimental evidence from coalition formation ultimatum games in Austria and Japan. Discussion Paper. University of Amsterdam.

Roth, A. E. (1995). Bargaining experiments. In J. Kagel \& A. Roth (Eds.), The handbook of experimental economics (pp. 253-348). Princeton: Princeton University Press.

Roth, A. E., Prasnikar, V., Okuna-Fujiwara, M., \& Zamir, S. (1991). Bargaining and market behavior in Jerusalem, Ljubljana, Pittsburg, and Tokyo: an experimental study. American Economic Review, 81, 1068-1095.

Smith, A. (2002). The theory of moral sentiments (K. Haakonsen edition), New York, Cambridge University Press. 